\title{
Do Tonkean macaques (Macaca tonkeana) perceive what conspecifics do and do not see?
}

Charlotte Canteloup, Emilie Piraux, Nicolas Poulin, Hélène Meunier

The understanding of the visual perception of others, also named visual perspective taking, is a component of Theory of Mind. Although strong evidence of visual perspective taking has been reported in great apes, the issue is more open to discussion in monkeys. We investigated whether Tonkean macaques (Macaca tonkeana) know what conspecifics do and do not see, using a food competition paradigm originally developed in great apes. We tested individuals in pairs, after establishing the dominance relationship within each pair. Twenty-one pairs were tested in four different conditions. In one condition, the subordinate had the choice between two pieces of food, one that was visible only to it and another that was also visible to the dominant. It was predicted that if the subordinate understands that the dominant cannot see both pieces of food because one is hidden from its view, the subordinate should preferentially go for the food visible only to itself. In the three other conditions, we varied the temporal and visual access to food for both individuals, to control for alternative explanations based on dominance. We recorded the first movement direction chosen by subjects, i.e. towards a) visible food b) hidden food or c) elsewhere; and the outcome of the test, i.e. the quantity of food obtained. Results showed that subordinates moved preferentially for the hidden food when released simultaneously with the dominant and also with a head start on the dominant. By contrast, dominants' choices of the two pieces of food were random. We also describe and discuss some of the strategies used by subordinates in these tests. According to the whole of our results, Tonkean macaques seem capable of visual perspective taking despite the fact that a low-level explanation as behavior reading has not been totally excluded. 
1 Do Tonkean macaques (Macaca tonkeana) perceive what conspecifics do and do not see?

2

3 Charlotte Canteloup ${ }^{1,2,3}$, Emilie Piraux ${ }^{1}$, Nicolas Poulin ${ }^{4}$, Hélène Meunier ${ }^{1,2,3}$

$4 \quad{ }^{1}$ Centre de Primatologie de l'Université de Strasbourg, Fort Foch, 67207 Niederhausbergen,

5 France

$6 \quad{ }^{2}$ Laboratoire de Neurosciences Cognitives et Adaptatives, UMR 7364, CNRS et Université de

7 Strasbourg, 12 rue Goethe, 67000 Strasbourg, France

$8{ }^{3}$ University of Strasbourg Institute for Advanced Study, 5 allée du Général Rouvillois, 67083

9 Strasbourg, France

$10{ }^{4}$ Centre Statistique de Strasbourg, IRMA, UMR 7501, 7 rue René Descartes, 67084 Strasbourg

11 Cedex, France

12

13 Corresponding author:

14 Charlotte Canteloup

15 Centre de Primatologie de l'Université de Strasbourg, Fort Foch, 67207 Niederhausbergen,

16 France

17 Laboratoire de Neurosciences Cognitives et Adaptatives, UMR 7364, 12 rue Goethe, 67000

18 Strasbourg, France

19 Email address: charlotte.canteloup@gmail.com 
22 The understanding of the visual perception of others, also named visual perspective taking, is a

23 component of Theory of Mind. Although strong evidence of visual perspective taking has been

24 reported in great apes, the issue is more open to discussion in monkeys. We investigated whether

25 Tonkean macaques (Macaca tonkeana) know what conspecifics do and do not see, using a food

26 competition paradigm originally developed in great apes. We tested individuals in pairs, after

27 establishing the dominance relationship within each pair. Twenty-one pairs were tested in four

28 different conditions. In one condition, the subordinate had the choice between two pieces of

29 food, one that was visible only to it and another that was also visible to the dominant. It was

30 predicted that if the subordinate understands that the dominant cannot see both pieces of food

31 because one is hidden from its view, the subordinate should preferentially go for the food visible

32 only to itself. In the three other conditions, we varied the temporal and visual access to food for

33 both individuals, to control for alternative explanations based on dominance. We recorded the

34 first movement direction chosen by subjects, i.e. towards a) visible food b) hidden food or c)

35 elsewhere; and the outcome of the test, i.e. the quantity of food obtained. Results showed that

36 subordinates moved preferentially for the hidden food when released simultaneously with the

37 dominant and also with a head start on the dominant. By contrast, dominants' choices of the two

38 pieces of food were random. We also describe and discuss some of the strategies used by

39 subordinates in these tests. According to the whole of our results, Tonkean macaques seem

40 capable of visual perspective taking despite the fact that a low-level explanation as behavior

41 reading has not been totally excluded. 

where someone else is looking" (Corkum \& Moore, 1995), a widespread behavior in nonhuman primates (Emery, 2000; Itakura, 2004). Gaze following may rely on simple mechanisms and is adaptive for detecting food during foraging, potential danger from predators, and important social information such as dominance-related interactions (Itakura, 2004). Moreover, it is considered as a prerequisite to complex forms of social cognition such as Theory of Mind (Emery, 2000). The use of another's gaze cues has indeed been implicated in higher order cognitive abilities such as visual perspective taking, deception and empathy (e.g. Anderson, 1998; Tomasello et al., 2005; Byrne \& Bates, 2010). In these cases, the observer understands that the observed individual is attending to a particular stimulus because the individual intends to do something with the visual target, or believes something about it. One of the biggest issues faced by comparative cognitive scientists is the extent to which gaze following reflects mental state attribution, especially in our closest relatives, the nonhuman primates (Shepherd 2010). (chimpanzees, Pan troglodytes: Povinelli \& Eddy, 1996; Call, Hare \& Tomasello, 1998; Tomasello, Hare \& Fogleman, 2001; gibbons, Hylobates pileatus, H. moloch, H. lar, Symphalangus syndactylus: Liebal \& Kaminski, 2012; rhesus macaques, Macaca mulatta:

61 Tomasello, Hare \& Fogleman, 2001; stump-tailed macaques, Macaca arctoides: Anderson \& 62 Mitchell, 1999; marmosets, Callithrix jacchus: Burkart \& Heschl, 2006). Conspecific models are 63 also effective (chimpanzees: Tomasello, Call \& Hare, 1998; Kano \& Call, 2014; bonobos, Pan 64 paniscus: Kano \& Call, 2014; orang-utans, Pongo abelii: Kano \& Call, 2014; rhesus macaques: 65 Emery et al., 1997; Tomasello, Call \& Hare, 1998; stumptailed macaques: Tomasello, Call \& 
66 Hare, 1998; pigtail macaques, Macaca nemestrina: Tomasello, Call \& Hare, 1998; sooty

67 mangabeys, Cercocebus atys torquatus: Tomasello, Call \& Hare, 1998; brown lemurs, Eulemur

68 fulvus and black lemurs, Eulemur macaco: Ruiz et al., 2009). Furthermore, some scholars have

69 recently reported flexibility in primate gaze following skills. For example, crested macaques

70 (Macaca nigra) reacted quicker to a change of gaze direction by a socially close conspecific

71 (Micheletta \& Waller, 2012), and long-tailed macaques (Macaca fascicularis) showed stronger

72 gaze following responses when a human's gaze shift was accompanied by a social facial

73 expression compared to a neutral expression (Goossens et al., 2008). The latter authors also

74 showed that macaques frequently looked back to the human's face when facing a human who

75 was looking at the ceiling where there was nothing of interest; chimpanzees do likewise (Call,

76 Hare \& Tomasello, 1998; Bräuer, Call \& Tomasello, 2005). Such results suggest that gaze

77 following is more than a simple reflex, but they provide no evidence that great apes understand

78 that the model is actually seeing something. This ability to understand what another subject can

79 see, also named visual perspective taking, is a component of Theory of Mind (Premack \&

80 Woodruff, 1978; Povinelli, Nelson \& Boysen, 1990).

81 The development of visual perspective taking in human infants is a two-step process,

82 according to Flavell (1992). For this author, infants near the age of two years can infer that

83 someone may see something that they do not, and vice versa (called Level 1 knowledge of visual

84 perception). Later, around three years of age (e.g. Moll \& Meltzoff, 2011), infants are able to

85 recreate the different visual appearances of something viewed by two persons from different

86 locations (called Level 2 knowledge of visual perception). Some researchers have sought to

87 determine whether nonhuman primates are capable of Level 1 perspective taking by testing great

88 apes and monkeys in various experimental paradigms. 
One of the most commonly used paradigms to study visual perspective taking in

90 nonhuman primates is the object-choice task. Typically in this task, a human experimenter hides

91 a piece of food under one of two containers and then attempts to notify the subject about the

92 location of the food by staring or pointing at the baited container. Great apes (chimpanzees: Call,

93 Agnetta \& Tomasello, 2000; orang-utans: Call \& Tomasello, 1998; gorillas: Peignot \&

94 Anderson, 1999) and monkeys (brown capuchins: Anderson, Sallaberry \& Barbier, 1995; rhesus

95 macaques: Anderson, Montant, \& Schmitt, 1996; marmosets: Burkart \& Heschl, 2007, but see

96 Burkart \& Heschl, 2006) often fail to request food from the correct container when the human's

97 gaze is the only cue. In another experiment (Povinelli \& Eddy, 1996), chimpanzees that were

98 trained to beg for food were confronted with two experimenters who could potentially give them

99 food: one could see them and one could not. Because the chimpanzees did not solicit food from a

100 human who could see them more than from one who could not see them, the authors concluded

101 that chimpanzees do not have a mentalistic understanding of seeing (i.e. knowing that seeing is

102 "about" something). Instead, according to Povinelli and Eddy (1996), chimpanzees have a

103 behaviorist appreciation of the behavior of others (i.e. "the chimpanzees' behavior is completely

104 governed by observable entities and events without recourse to reasoning about unobservable

105 mediating mental states", footnote $1 \mathrm{p} \mathrm{25).}$

106 Some researchers (Johnson \& Karin-D’Arcy, 2006 for review) have criticized the object-

107 choice task as it diverges greatly from social conditions in which primates naturally use visual

108 perspective taking; in other words it lacks ecological validity. Specifically, the object-choice task

109 puts the subject in a cooperative situation with a human partner, an unusual context unlikely to

110 occur in nonhuman primates' natural daily life. Therefore, acknowledging the importance of

111 competition in primates' normal lives (Byrne \& Whiten, 1988), researchers have developed 
112 alternative paradigms involving an intraspecific competitive context to test visual perspective

113 taking in a more ecologically valid way (Hare, 2001). In the pioneering experiment by Hare et al.

114 (2000), two chimpanzees - a dominant and a subordinate - were tested in a food competition

115 situation. The subjects were placed in opposite rooms with food pieces positioned in a room

116 situated centrally between the dominant's room and the subordinate's room. In the test, one piece

117 of food was visible to both individuals while the other, hidden behind a barrier, was visible only

118 to one of the two subjects. Hare et al. (2000) hypothesized that when subordinates saw both

119 pieces of food, they would head for the hidden food more often than the visible one, which

120 would be evidence that they could take the visual perspective of their dominant conspecific.

121 Subordinate chimpanzees did indeed preferentially go for the food that only they could see when

122 released simultaneously with the dominant (Hare et al., 2000; Bräuer, Call \& Tomasello, 2007).

123 The same result was obtained when subordinates were released shortly before the dominant,

124 forcing them to make a choice of direction towards one of the two pieces of food before the

125 dominant that not depends on the dominant's intention movements towards food (Hare et al.,

126 2000; Hare, Call \& Tomasello, 2001; Bräuer, Call \& Tomasello, 2007). However, these authors

127 reported an alternative hypothesis named the intimidation hypothesis: subordinates could choose

128 the food the dominant was not looking at throughout the space under the trapdoor allowing

129 subject to see the testing area. In order to rule out this hypothesis, Hare and collaborators

130 assessed two controls. A first control was made nine months later in which the dominant's door

131 was raised for some seconds after the baiting procedure and finally closed. Next, the

132 subordinate's door was opened allowing the subordinate to enter in the testing area. The

133 dominant was then released after the subordinate had adopted its first direction choice.

134 Researchers reported that subordinates approached the hidden piece of food more often than the 
135 visible one. A second control placed the dominant in a situation in which it could see always a

136 single piece of food hidden from the subordinate's view. In this control, two experimental

137 conditions were performed: in one, both trapdoors were raised allowing both subjects to see the

138 occluders but only the dominant could see the hidden piece of food. In this condition, the

139 subordinate had the opportunity to read the dominant's behavior and locate food whereas in the

140 second condition, only the subordinate's door was raised, so it could not read the dominant's

141 behavior. Hare and collaborators reported that subordinates chose to head for one of the two

142 occluders at random, so they did not use the dominant's behavior to locate food, which

143 strengthen the hypothesis that chimpanzees know what conspecifics do and do not see.

144 Few comparable studies have been done on monkeys, with equivocal results regarding

145 their visual perspective taking abilities. On one hand, subordinate capuchins (Sapajus apella)

146 have been reported to prefer retrieving hidden food when released at the same time as dominants;

147 however, they did not approach hidden food first when released with a short head start. Thus, 148 capuchins appeared to base their choice on behavior reading rather than perspective taking (Hare

149 et al., 2003). Marmosets reportedly behaved like chimpanzees (Burkart \& Heschl, 2007) in

150 conditions similar to those designed by Hare and colleagues $(2000 ; 2003)$ but the authors also

151 acknowledged a possible behavior reading explanation. On the other hand, some lemur species

152 (ring-tailed lemur, Lemur catta: Sandel, MacLean \& Hare, 2011; MacLean et al., 2013; Bray,

153 Krupenye \& Hare, 2014; black lemur; brown lemur; Coquerel's sifaka, Propithecus coquereli:

154 MacLean et al., 2013) and rhesus macaques (Macaca mulatta: Flombaum \& Santos, 2005; Bray,

155 Krupenye \& Hare, 2014) have been shown to preferentially steal food from a human competitor

156 who cannot see the food rather than one who can see it. In addition, Overduin-de Vries et al.

157 (2014) reported that long-tailed macaques understood what a conspecific competitor could see; 
158 those authors ruled out a behavior reading explanation because only subordinates could see the

159 dominants when making their choice, whereas dominants had no visual access to food or the

160 subordinates either before or during the trial. In this situation dominants could not show special

161 interest in one of the two pieces of food, and consequently they had no inhibiting effect on the

162 subordinates. Social cognitive studies in macaques focused essentially on despotic species such

163 as rhesus and long-tailed macaques, neglecting tolerant species as their Sulawesian cousins. How

164 specific social dynamics affect cognitive abilities as Theory of Mind abilities is poorly

165 understood and studies of socio-cognitive capacities tend to overlook the potential influence of

166 social characteristics of the species. Studying socially tolerant species could thus provide insights

167 about the influence of sociocultural environment on perception reading abilities and can help to

168 elucidate the ecological and social pressures that favoured the evolution of Theory of Mind.

169 Social tolerance being one of the important factors for social complexity, we would expect more

170 complex cognitive skills for a more socially tolerant species compared to a more despotic one.

171 Testing a tolerant species in a competitive context also allows investigation of the contextual

172 features that underlie such cognitive skills in species with different ecological and social

173 characteristics.

174 In this context, we tested a tolerant macaque species that has not been extensively 175 studied, the Tonkean macaque (Macaca tonkeana), in an experiment inspired by Hare et al. $176(2000 ; 2003)$, to investigate their understanding of visual perception. For this, we used an 177 equivalent of the "occluder test" from Hare et al. (2000) in four different experimental 178 conditions. In conditions 1 and 2, the subordinate had visual access to two pieces of food: one 179 positioned on the top of the visual barrier, visible to the subject and to the dominant, and one 180 positioned under the barrier, thus only visible to the subject. The difference between conditions 1 
181 and 2 was that in condition 1, both monkeys had access to the testing area at the same time,

182 whereas in condition 2 the subordinate was released slightly earlier than the dominant. Thus,

183 condition 2 was a control aimed at ruling out the possibility subordinates might simply react to

184 the dominant's intention movements towards the visible food. In conditions 3 and 4 , the

185 dominant had visual access to both pieces of food whereas the subordinate saw only one.

186 Conditions 3 and 4 differed in that in condition 4, both monkeys had access to the testing area at

187 the same time, whereas in condition 3, the dominant was released with a short head start on the

188 subordinate. These two conditions were run to verify that macaques do not have a general

189 preference for hidden food and that dominants do not exhibit specific behavioral strategies in the

190 presence of subordinates. We expected that, as in long-tailed macaques, subordinate Tonkean

191 macaques would move preferentially for the hidden food in conditions 1 and 2, whereas

192 dominants would show no preference for either piece of food in conditions 3 and 4.

193

194

195 METHODS

196

197 Ethical note

198

199

The procedures used here adhere to the French legal requirements for the Use of Animals

200 in Research. This experiment was approved by the Animal Experiment Committee of the Centre

201 de Primatologie de l'Université de Strasbourg and by the CREMEAS Ethics Committee

202 (Approval for conducting experiments on primates $n^{\circ}$ AL/46/53/02/13).

203 
204 Subjects

205

206 The subjects were eleven Tonkean macaques (eight males aged two - 11 years and three 207 females aged four - 17 years), tested in 21 dyads, all born and raised at the Centre de 208 Primatologie de l'Université de Strasbourg, France. Four subjects were tested as dominant only, 209 one as subordinate only and six as both dominant and subordinate (see Table 1 for details). 210 Subjects lived in a social group of 28 individuals in a one-acre wooded park with access to a 20 $211 \mathrm{~m}^{2}$ heated indoor housing area. The monkeys' diet consisted of commercial pellets and water ad 212 libitum, and fruits and vegetables twice a week, after experimental sessions.

216 Apparatus

Subjects were tested in dyads in an outdoor experimental enclosure adjacent to their park,

219 which allowed individuals to participate voluntarily. The experimental enclosure consisted of 220 three compartments interconnected by trapdoors (Fig. 1): an area "A" $(430 \times 290 \mathrm{~cm}$ and $190 \mathrm{~cm}$

221 high $)$ directly connected to the park; a middle compartment "B" or testing area $(290 \times 290 \mathrm{~cm}$

222 and $190 \mathrm{~cm}$ high $)$, and an area "C" $(140 \times 290 \mathrm{~cm}$ and $190 \mathrm{~cm}$ high $)$. In compartment B two 223 breeze blocks $(49 \times 38 \mathrm{~cm}$ and $15 \mathrm{~cm}$ high $)$, served as visual barriers; they were placed in the 224 middle of the area, equidistant to the trapdoors and separated by $80 \mathrm{~cm}$. The three compartments 225 were connected by double-layered trapdoors $(42 \times 52 \mathrm{~cm})$ consisting of one transparent Plexiglas 
226 door doubled with an opaque metal door. The two layers of the trapdoors could be opened

227 independently.

228

229

--- INSERT FIG. 1 APPROXIMATELY HERE ---

230

231

Establishment of dominance hierarchy within the group

232

233

The first step in this study was to determine dominance relationships between the

234 subjects. This was done in two ways: firstly, by establishing the dominance hierarchy within the 235 group, and secondly, verifying the dominance relationship within tested dyads.

236 The within-group dominance hierarchy was determined in 25 sessions of food 237 competition tests. A bottle filled with diluted sweet syrup was attached to the wire mesh fencing 238 inside the macaques' park. This induced food competition for access to the syrup, and the 239 experimenter recorded agonistic interactions in the vicinity of the bottle. At the end of each 240 interaction, each participant was recorded as "winner" or "loser." From the resulting global 241 matrix the dominance hierarchy was obtained using Matman 1.1 (de Vries, Netto, Hanegraaf, 242 1993); it was significantly linear $\left(h^{\prime}=0.39 ; P=0.00009\right)$. Then we calculated hierarchical rank 243 differences for each dyad to be tested by subtracting the rank of the subordinate from that of the 244 dominant (see raw data for details).

245

246 Establishment of dominance relationship within dyads 247 

area. Twenty-one dyads were tested between April and June 2014. One subject was placed in area $\mathrm{A}$ and the other in the area $\mathrm{C}$ (Fig. 1). The opaque trapdoors were lowered to hide the

251 baiting procedure from each monkey. A slice of banana was placed centrally in the testing area,

252 exactly half way between the two breeze blocks. The experimenter (EP) then simultaneously 253 raised the opaque layers of the two trapdoors to allow the subjects to see into the testing area 254 through the transparent layers. Five seconds after the two subjects were in position behind the 255 Plexiglas trapdoors and after having looked into the testing area, the experimenter 256 simultaneously raised the transparent layers, allowing the monkeys to enter the testing area. 257 Whichever monkey picked up the slice of banana was considered dominant in this trial. We 258 performed 10 such tests per dyad and tested the significance of the difference in successes using 259 a binomial test for each dyad.

260

Experimental procedure

262

The experiment took place in the three experimental areas described above (Fig. 1). For each trial, one slice of banana was placed on top of one of the two breeze blocks, and the other was put inside and near the back of the other breeze block, so that only one of the two subjects could see both banana pieces (subject in C in Fig. 1). Which piece of food went in which location was randomized across trials. The experiment consisted of four experimental conditions as

268 follows: In conditions 1 and 2, the subordinate could see both pieces of food, but in condition 1

269 both subordinate and dominant were released into the testing area simultaneously, whereas in 270 condition 2 the subordinate was released slightly before the dominant (the dominant was released 
271 as soon as the subordinate's entire body was in the testing area). In conditions 3 and 4 the

272 dominant could see both pieces of food, but in condition 3 the dominant was released slightly

273 before the subordinate, whereas in condition 4 both individuals were released simultaneously. In

274 cases when the individual released first (conditions 2 and 3) did not fully enter the testing area,

275 the other individual was released 60 seconds after the first individual. Because subjects were

276 tested opportunistically (i.e., they had free access to the experimental area and were never forced

277 to participate), we ran between 1 and 22 trials of the four different experimental conditions

278 following a same random list of trials per dyad (see data acquisition sheet on raw data for

279 details), resulting in a total of 1 to 66 trials per dyad (total mean of trials per dyad $=20.7 \pm 4.3$;

280 see Table 2. for details), with a maximum of twenty trials per condition in total (ten trials for 281 each breeze block). . Each trial started when at least one of the two transparent trapdoors was 282 opened, and ended when the two pieces of food were picked up.

283

284

--- INSERT TABLE 2 APPROXIMATELY HERE ---

285

286

Data and reliability analyses

287

288

All experiments were recorded using a video camera HD (Canon, Legria HF S20) and 289 data were later coded by CC using the software VLC 2.1.5. Two variables were measured: a) the first movement direction taken by individuals: (i) hidden: head and chest oriented towards the

291 hidden banana; ii) visible: head and chest oriented towards the visible banana; iii) elsewhere: the 292 subject did not enter in the testing area or entered and sat down in front of the trapdoor or entered 293 and crossed the testing area between the two breeze blocks); b) the outcome of the test: (i) 
294 outcome 1: the dominant gets both pieces of food ii) outcome 2: the subordinate gets both pieces

295 of food; iii) outcome 3: the dominant gets the visible piece of food and the subordinate gets the

296 hidden one; iv) outcome 4: the subordinate gets the visible piece of food and the dominant gets

297 the hidden one). In some cases, subjects behaved as if they understood that two pieces of food

298 were present and began searching both locations, even on trials in which they only had visual

299 access to one piece of food. In these trials, just after having retrieved the visible piece of food,

300 some dominants systematically visited the other occluder on the subordinate's side to retrieve the

301 hidden banana. We excluded these trials from the analysis. Twenty-nine trials were removed due

302 to errors during experiments (e.g. one subject was released in the testing area too late). Ten

303 additional trials were removed from the analysis due to the loss of two video clips (trial $\mathrm{n}^{\circ} 1$ for

304 the dyad Wotan-Yannick and trials 4 to 12 for the dyad Shan-Yannick). For reliability analysis, a

305 random twenty percent of the videos were analysed by HM. Inter-observer agreements were

306 excellent for both the first movement direction (Cohen's $\kappa=0.94$ ) and the outcome of the test

307 (Cohen's $\kappa=0.99)$.

308

309 Statistical analysis

310

Analysis focused on experimental configurations where subjects chose between the two

312 pieces of food, namely conditions 1 and 2 for subordinates and conditions 3 and 4 for dominants.

313 In order to deal with pseudoreplication, we used several generalized linear mixed models

314 (GLMMs) with identities of the dominant, the subordinate and the dyad as random effects. Each

315 combination of the random variables was used in different models, and backward selection of the

316 random effects based on Likelihood Ratio Test (LRT; Lewis, Butler \& Gilbert, 2011) was 
317 performed for each model. In each model, experimental condition, trial number and hierarchical

318 rank difference were assessed as fixed effects. We used these models to determine which factors

319 most influenced the subjects' choice of direction and the outcome of the test.

320 Regarding subject choice, the analyses were divided into two sub-questions: 1) Which

321 factors explain the choice of direction or no choice? 2) When subjects made a choice, which

322 factors explain the direction chosen, i.e. hidden or visible? To answer these questions, GLMMs

323 (GLMM1 to GLM4) for data following a binomial distribution with a logit link function were

324 fitted. Additionally, to investigate potential learning effects on the first movement direction and

325 for a better comparison with results of previous studies on other species, we analysed only the

326 two first trials per dyad using Wilcoxon signed rank tests.

327 Concerning the outcome of the test, we fitted a GLMM for each possible outcome 328 (GLMM5 to GLMM8) to investigate whether the outcome depended on the experimental 329 condition. Some outcomes did not occur for some conditions. Hence, we fitted: i) a model for 330 outcome 1 on the basis of the four experimental conditions; ii) a model for outcome 2 on the 331 basis of conditions 1 and 2; iii) a model for outcome 3 on the basis of conditions 1 and 2 and iv) 332 a model for outcome 4 on the basis of conditions 3 and 4 . Moreover, to investigate potential 333 learning effects on outcome, and to better compare with the results of previous studies on other 334 species, we analysed only the two first trials per dyad using Wilcoxon matched pairs tests. To investigate whether subordinates obtained both pieces of food (outcome 2) 336 significantly more often as a function of their first movement direction (i.e. towards the visible or 337 the hidden food), we fitted a GLM (GLM9) including their first direction as a fixed effect. 
Tukey corrections were applied when performing multiple comparison tests between

339 experimental conditions. All models were performed using R 3.1.2's package lme4 (Bates et al., 2014) and Wilcoxon tests were done with GraphPadInstat 3.1 with alpha set at 0.05 .

\section{First movement direction: towards food or not?}

\section{RESULTS}

The best-fitting model on the basis of LRT was the one with the identity of the dominant as the only random effect (GLMM1; see details of each model in Table_S1). According to this model, subordinates headed for food rather than elsewhere when they saw both pieces of food and were released at the same time as the dominants (condition $1 ; \mathrm{z}=2.61 ; P=0.009$ ), and with a head start (condition 2; $\mathrm{z}=5.44 ; P<0.0001$ ) on the dominants (Fig. 2). In contrast, they mostly headed elsewhere instead of towards food when they saw only one piece of food and were released after the dominant (condition $3 ; \mathrm{z}=-2.72 ; P=0.007$ ). When they saw only one piece of food and were released at the same time as the dominant, subordinates did not show any preference for approaching food or going elsewhere (condition $4 ; \mathrm{z}=-0.18 ; P>0.05$ ). The probability that the subordinates would first go towards food increased significantly across trials $(\mathrm{z}=2.74 ; P=0.006)$ the behavior of subordinates in these two conditions. The best model on the basis of LRT was the one with only the dyad as random effect. According to this model, subordinates headed for food 
361 significantly more than elsewhere when they were released before the dominant than were

362 released at the same time as the dominant $(\mathrm{z}=3.33 ; P=0.0009)$. The greater the hierarchical

363 rank difference, the less likely subordinates headed towards food $(\mathrm{z}=-2.26 ; P=0.02)$.

364

Dominants headed directly for food in all conditions (Fig. 2; see Table_S2 for details).

365

366

--- INSERT FIG. 2 APPROXIMATELY HERE ---

367

368

First direction choice: hidden or visible food?

369

370

The best-fitting model for when subordinates headed for food (hidden or visible)

371

concerning conditions 1 and 2 was the one with the identity of the tested dyad as the only

372

random effect (GLMM3). According to this model, subordinates headed for hidden food

373 significantly more than visible food when they were released simultaneously (condition $1 ; \mathrm{z}=$

4.64; $P<0.0001$ ) and with a head start on the dominant (condition $2 ; \mathrm{z}=2.87 ; P=0.004$ ) (Fig.

3). As the number of trials increased, the less subordinates headed for the hidden food first ( $\mathrm{z}=$ -

2.91; $P=0.004$ ), and thus the more they headed for the visible food first. The hierarchical rank difference had no effect on whether the subject chose between hidden and visible food $(\mathrm{z}=$ $0.27 ; P>0.05)$. Regarding only the two first trials per dyad, subordinates headed for hidden food significantly more than visible food in conditions $1(\mathrm{~W}=54 ; \mathrm{T}+=60 ; \mathrm{T}-=-6 ; P=0.01)$ and 2 $(\mathrm{W}=104 ; \mathrm{T}+=112 ; \mathrm{T}-=-8 ; P=0.002)$. When they saw both pieces of food, subordinates headed significantly more frequently towards the hidden food when they were released at the

382 same time than when they were released before the dominant (Fig. $3 ; \mathrm{z}=-4.11 ; P<0.0001$ ).

383 Regardless of random effects, all models assessed for dominants' first movement direction 
384 towards food reported a variance for the random effects equal to zero (i.e. each random

385 parameter in each GLMM is equal to zero). As these parameters are meant to deal with 386 dependence among repeated measurements, dominants' data could be considered as independent, 387 allowing us to perform a GLM and not a GLMM that fit our data better (GLM4). When fitting 388 the GLM, none of the explanatory variables had a significant effect and none of the probabilities 389 for both directions differed significantly from 0.5. Thus, dominants showed no significant 390 preference for moving towards hidden or visible food in the two conditions in which they had 391 visual access to the two pieces of food (conditions 3 and 4; Fig. 3; $P>0.05$ ). Regarding only the 392 two first trials per dyad, dominants again showed no preference for hidden or visible food in both 393 conditions $3(\mathrm{~W}=20 ; \mathrm{T}+=24 ; \mathrm{T}-=-4 ; P>0.05)$ and $4(\mathrm{~W}=0 ; \mathrm{T}+=52.5 ; \mathrm{T}-=-52.5 ; P>0.05)$ 394 in their two first trials per dyad. --- INSERT FIG. 3 APPROXIMATELY HERE ---

397

Outcome of the test

399

400 The best models were those with the identity of the dominant as a random effect. 401 Dominants obtained both pieces of food (outcome 1; GLMM5) significantly more when they 402 saw both pieces of food and were released at the same time (condition $4: \mathrm{z}=8.01 ; P<0.001$ ) 403 and also with a short head start on the subordinate (condition $3: \mathrm{z}=8.60 ; P<0.001$ ) than when 404 they saw only one piece of food and were released at the same time as subordinates (condition 1;

405 Fig. 4). Dominants obtained both pieces of food (outcome 1) significantly more when they saw 406 both pieces of food and were released at the same time (condition $4: \mathrm{z}=8.27 ; P<0.001$ ) and 
407 also with a short head start on subordinates (condition $3: \mathrm{z}=8.79 ; P<0.001$ ) than when they

408 saw only one piece of food and were released after a short head start for subordinates (condition

409 2). Moreover, dominants tended to obtain both pieces of food more often in condition 3 than in

410 condition $4(\mathrm{z}=-2.40 ; P=0.073)$. The number of trials and the hierarchical rank difference

411 between the tested individuals had no significant effect on the probability of outcome 1 (Fig.4; $P$ $412>0.05)$.

413 Subordinates were significantly more likely to obtain both pieces of food (outcome 2;

414 GLMM6) when they were released before the dominant (condition 2) than when they were 415 released at the same time as the dominant (condition $1 ; \mathrm{z}=4.02 ; P<0.0001 ;$ Fig. 4). Moreover, 416 subordinates obtained the two pieces of food significantly more often with increasing trials $(\mathrm{z}=$ $4172.64 ; P=0.008)$. The hierarchical rank difference between the two individuals had no significant 418 effect on the probability of outcome $2(\mathrm{z}=0.95 ; P>0.05)$.

Dominants got the visible food and the subordinate the hidden one (outcome 3; GLMM7) 420 significantly more often when the subordinate saw both pieces of food and was simultaneously 421 released (condition 1; Fig. 4) than when released with a short head start on the dominant 422 (condition $2 ; \mathrm{z}=-4.13 ; P<0.0001)$. As the number of trials $(\mathrm{z}=-2.23 ; P=0.03)$ and the 423 hierarchical rank difference increased $(\mathrm{z}=-2.29 ; P=0.02)$, the more likely was the dominant to 424 retrieve the visible food and the subordinate the hidden one.

425 Occurrences of the subordinate getting the visible food and the dominant the hidden one 426 (outcome 4; GLMM8) were significantly more frequent when the dominant saw both pieces of 427 food and was released at the same time (condition $4 ; \mathrm{z}=2.23 ; P=0.03$ ) than when released 428 before the subordinate (condition 3; Fig. 4). Neither number of trials nor the hierarchical rank 429 difference had a significant effect on the probability of outcome $4(P>0.05)$. 
431 than the visible one significantly more in conditions $1(\mathrm{~W}=66 ; \mathrm{T}+=66 ; \mathrm{T}-=0 ; \mathrm{P}=0.001)$ and

$4322(\mathrm{~W}=153 ; \mathrm{T}+=153 ; \mathrm{T}-=0 ; \mathrm{P}<0.0001)$. By contrast, dominants did not obtain one of the two 433 pieces of food significantly more than the other in condition $3(\mathrm{~W}=4 ; \mathrm{T}+=5 ; \mathrm{T}-=-1,0 ; P>$ $4340.05)$ or condition $4(\mathrm{~W}=8 ; \mathrm{T}+=9 ; \mathrm{T}-=-1,0 ; P>0.05)$.

435

436

--- INSERT FIG. 4 APPROXIMATELY HERE ---

437

438

Effect of first direction on the outcome

439

440

Three subordinates (Lady, Nenno and Yannick) of the seven tested obtained both pieces

441 of food when they first headed for the visible one (Table. 3). The best model concerning outcome

4422 for observations made when subordinates headed first for visible food in conditions 1 and 2 443 was the one with no random effect (GLM9). This model reported a significant effect of first 444 movement direction by subordinates on the likelihood of outcome 2: when subordinates first 445 headed for visible food they obtained the two pieces significantly more than when they first 446 headed for the hidden one $(\mathrm{z}=-6.72 ; P<0.0001)$.

447

448 --- INSERT TABLE 3 APPROXIMATELY HERE ---

449

450

451

DISCUSSION

452 
454 proposed by Hare et al. (2000) in which a subordinate subject could choose to retrieve a food

455 item hidden from the view of a dominant conspecific and another one visible to both the

456 dominant and itself. Our hypothesis was that if subordinates but not dominants preferentially

457 went for the hidden food, this could be evidence of visual perspective taking in this macaque

458 species. In agreement with previous studies on great apes (chimpanzees: Hare et al., 2000; Hare,

459 Call \& Tomasello, 2001; Bräuer, Call \& Tomasello, 2007) and monkeys (rhesus macaques:

460 Flombaum \& Santos, 2005; long-tailed macaques: Overduin-de Vries, Spruijt, \& Sterck, 2014),

461 our results provide support for this hypothesis in a tolerant macaque species: the Tonkean

462 macaque. However, we cannot completely rule out an alternative explanation, namely that

463 subordinates just avoided visible food potentially looked at by dominants throughout the

464 transparent trapdoor.

465 Subordinates preferentially headed for food (hidden or visible) when they saw both pieces

466 of food and were released simultaneously or with a short head start on the dominant, whereas

467 dominants always went for food. This result validates the naturalistic experimental paradigm

468 used here: placing subordinates in a food competition situation with dominants. In previous

469 studies with chimpanzees (Karin-D’Arcy \& Povinelli, 2002; Bräuer, Call \& Tomasello, 2007),

470 marmosets (Burkart \& Heschl, 2007) and capuchins (Hare et al., 2003), limited space probably

471 caused subjects to engage in scramble competition rather than use perspective taking skills. The

472 size and spatial arrangement of our testing area clearly induced a competitive situation

473 appropriate for revealing perspective taking by subordinate macaques. Moreover, the greater the

474 hierarchical rank difference between the two members of each was, the less the subordinate

475 headed for food, further supporting the validity of the competitive situation. 
It seems reasonable to suggest that the experimental context - collaborative or

477 competitive - might have a lesser impact on a species with a more fluid social organization than

478 species demonstrating a more strict social system. However, the evidence for this is equivocal.

479 One the one hand, we previously failed to demonstrate that Tonkean macaques distinguish

480 between open and closed eyes in a cooperative interspecific context (Canteloup, Bovet, \&

481 Meunier, 2015). On the other hand, Costes-Thiré et al. (2015a; 2015b) found no evidence of

482 auditory perspective taking in Tonkean macaques tested in a food competition situation with a

483 human experimenter, or intention reading abilities when they had to cooperate for food with a

484 human partner.

485 In the present study, when they saw both pieces of food subordinates preferentially

486 headed for the hidden food when they were released simultaneously with the dominant. The

487 same result emerged when subordinates were released slightly before the dominant, allowing

488 them to choose independently of the dominant's choice. Indeed, when released at the same time,

489 the subordinate could head for the hidden food because at the same time the dominance headed

490 for the only food it could see, namely the visible one.

491 For this reason we ran more trials than is usual in these kinds of studies (e.g. Hare et al., 2000).

492 This could lead to the criticism that, in our study, subordinates simply learned the best way to get

493 food, requiring no perspective-taking ability. To deal with this explanation, we ran the same

494 statistical analyses as Hare et al. (2000) on only the two first trials for each dyad, and found

495 exactly the same results as obtained using all the data. These results suggest that, like other

496 primate species studied (Hare et al., 2000; Hare, Call \& Tomasello, 2001; Bräuer, Call \&

497 Tomasello, 2007; Overduin-de Vries, Spruijt, \& Sterck, 2014), Tonkean macaques appear

498 capable of understanding what a conspecific can and cannot see. This conclusion is strengthened 
499 by the fact that dominants showed no preference for either the hidden or visible food. This 500 finding rules out the possibility that macaques have a general preference for hidden food. 501 However, a final alternative explanation invoking behavior reading rather than perspective taking 502 may be proposed. According to the "evil eye hypothesis" (Kaminski, Call, \& Tomasello, 2008) 503 and other authors" "behavioral rules" accounts (Heyes, 1998; Povinelli \& Vonk, 2003; 2004), the 504 subordinates' behavior could be influenced by what it sees the dominant doing through the 505 transparent trapdoor. In other words, subordinates might prefer to head for the hidden food 506 because the visible one will have been watched by the "evil eye" of the dominant, and thus 507 considered as "contaminated". They might also have learned that food coveted by the dominant 508 is out of bounds. Unfortunately, our experimental design does not allow us to refute this 509 alternative explanation; the use of one-way mirrors as in Overduin-de Vries et al.'s (2014) study 510 on long-tailed macaques (2014) might be an appropriate procedure that would allow to rule out 511 this low-level explanation.

512 Given that visual perspective taking has been demonstrated in a phylogenetically very 513 close species, the long-tailed macaque (Overduin-de Vries, Spruijt, \& Sterck, 2014), we think it 514 likely that this ability has evolved as common trait shared by macaque species. Some of the 515 individual strategies that we observed further support our view that Tonkean macaques are 516 capable of visual perspective taking. One such strategy used by subordinates consisted of 517 traversing and leaving the testing area, and if followed by the dominant, rapidly doubling back to 518 retrieve the hidden food (see video_S3). Another strategy was to head first for the visible food. 519 Indeed, as the number of trials increased, the less the subordinates headed for the hidden food 520 first. Moreover, when they saw both pieces of food, subordinates headed for hidden food 521 significantly less often when released with a short head start on the dominant than when released 
522 simultaneously. Surprisingly, when released before the dominant, subordinates moved first to the

523 visible food in almost thirty percent of cases. In terms of the outcome of the test, in this

524 condition, subordinates often managed to obtain both pieces of food when they first headed for

525 the visible food, and this occurred increasingly frequently over repeated trials. On the basis of

526 these observations we conclude that three of the seven subordinates tested adopted this

527 alternative strategy to get both pieces of food by taking into account what the dominant could

528 and could not see. This kind of strategy was recently reported in a more despotic macaque

529 species: the long-tailed macaque (Overduin-de Vries, Spruijt, \& Sterck, 2014), and similar

530 behavior was reported in Tonkean macaques by Ducoing and Thierry (2003). In the latter study,

531 subordinates stopped approaching a hidden fruit, avoided being followed, or took a wrong

532 direction when monitored by a dominant unaware of the location of the food. Together, these

533 observations raise questions about the mechanisms underlying these strategies. Do they rely on

534 relatively simple cognitive processes, such as withholding information due to behavioral

535 inhibition caused by the presence of the dominant, or are more complex cognitive processes

536 involved, such as tactical deception? In other words, do Tonkean macaques learn by operant

537 conditioning to anticipate the consequences of their acts on the behaviors of others or/and do

538 they intentionally attempt to manipulate the knowledge of others? Further investigations are

539 necessary to be able to answer these unresolved questions.

540 To conclude, our experiment adds to the growing literature on components of Theory of

541 Mind in nonhuman primates, especially in monkeys and notably in macaques (e.g. Flombaum \&

542 Santos, 2005; Santos, Nissen, \& Ferrugia, 2006; Costes-Thiré et al., 2015a; 2015b; Overduin-de

543 Vries, Spruijt, \& Sterck, 2014). Like chimpanzees (Bräuer, Call \& Tomasello, 2007; Hare et al.,

544 2000; Hare, Call \& Tomasello, 2001; Krachun \& Call, 2009) and despotic Old World monkeys 
545 as rhesus (Flombaum \& Santos, 2005) and long-tailed macaques (Overduin-de Vries, Spruijt, \&

546 Sterck, 2014), Tonkean macaques, socially more tolerant, seem capable of level 1 of visual

547 perspective taking, although further experiments are needed to rule out a low level alternative

548 explanation. Additionally, we observed an alternative strategy developed by subordinates to

549 obtain all the available food. These findings show the advantages of a naturalistic experimental

550 paradigm that recreates socio-cognitive problems that nonhuman primates face in their natural

551 environment.

552

553

\section{ACKNOWLEDGMENTS}

555

556

The authors are grateful to Nicolas Herrenschmidt, Yves Larmet and the whole team of

557 the Centre de Primatologie de 1'Université de Strasbourg for allowing them to conduct this study.

558 The authors are particularly thankful to Steve Lapp, Adrien Panter and Jean-Marc Woock for

559 building the experimental apparatus and for their technical assistance. James R. Anderson and

560 Nailah Ford Burrell are warmly thanked for editing the English of the manuscript. Finally we

561 thank Juliane Kaminski, Editor of PeerJ and the two anonymous referees for their valuable 562 comments on the manuscript.

563

564

565

REFERENCES

566 
567 Anderson JR, Sallaberry P, Barbier H. 1995. Use of experimenter-given cues during object$568 \quad$ choice tasks by capuchin monkeys. Animal Behaviour 49: 201-208.

569 Anderson JR, Montant M, Schmitt D. 1996. Rhesus monkeys fail to use gaze direction as an 570 experimenter-given cue in an object-choice task. Behavioural Processes 37: 47-55.

571 Anderson JR. 1998. Social stimuli and social rewards in primate learning and cognition. $572 \quad$ Behavioural Processes 42: 159-175.

573 Anderson JR, Mitchell RW. 1999. Macaques but not lemurs co-orient visually with humans. $574 \quad$ Folia Primatologica 70: 17-22.

575 Bates D, Maechler M, Bolker B, Walker S. 2014. lme4: Linear mixed-effects models using 576 Eigen and S4. ArXiv e-print; submitted to Journal of Statistical Software: $577 \quad$ http://arxiv.org/abs/1406.5823

578 Bräuer J, Call J, Tomasello M. 2005. All great apes species follow gaze to distant locations and 579 around barriers. Journal of Comparative Psychology 119(2): 145-154.

580 Bräuer J, Call J, \& Tomasello M. 2007. Chimpanzees really know what others can see in a 581 competitive situation. Animal Cognition 10: 439-448.

582 Bray J, Krupenye C, Hare G. 2014. Ring-tailed lemurs (Lemur catta) exploit information about 583 what others can see but not what they can hear. Animal Cognition 17: 735-744.

584 Burkart JM, Heschl A. 2006. Geometrical gaze following in common marmosets (Callithrix 585 jacchus). Journal of Comparative Psychology 120 (2): 120-130.

586 Burkart JM, Heschl A. 2007. Understanding visual access in common marmosets, Callithrix 587 jacchus: perspective taking or behaviour reading? Animal Behaviour 73: 457-469.

588 Byrne RW, Bates LA. 2010. Primate social cognition: uniquely primate, uniquely social, or just 589 unique? Neuron 65: 815-830. 
590 Byrne RW, Whiten A. 1988. Machiavellian intelligence: social expertise and the evolution of 591 intellect in monkeys, apes, and humans. Oxford, England: Clarendon Press.

592 Call J, Hare BA, Tomasello M. 1998. Chimpanzee gaze following in an object-choice task. 593 Animal Cognition 1: 89-99.

594 Call J, Tomasello M. 1998. Distinguishing intentional from accidental actions in orang-utans 595 (Pon- pygmaeus), chimpanzees (Pan troglodytes), and human children (Homo sapiens). 596 Journal of Comparative Psychology 112: 192-206.

597 Call J, Agnetta B, Tomasello M. 2000. Cues that chimpanzees do and do not use to find hidden $598 \quad$ objects. Animal Cognition 3: 23-34.

599 Canteloup C, Bovet D, Meunier H. 2015. Do Tonkean macaques (Macaca tonkeana) tailor their 600 gestural and visual signals to fit the attentional states of a human partner? Animal 601 Cognition 18: 451-461.

602 Corkum V, Moore C. 1995. Development of joint visual attention in infants. In C. Moore, \& P. J. 603 Dumham (Eds.), Joint attention (pp. 61-84). Hillsdale, NJ: Lowrence Earlbaum Associates. 604 Costes-Thiré M, Levé M, Uhlrich P, De Marco A, Thierry B. 2015a. Lack of evidence that 605 Tonkean macaques understand what others can hear. Animal Cognition 18: 251-258.

606 Costes-Thiré M, Levé M, Uhlrich P, Pasquaretta C, De Marco A, Thierry B. 2015b. Evidence 607 that monkeys (Macaca tonkeana and Sapajus apella) read moves, but no evidence that 608 they read goals. Journal of Comparative Psychology, Advance online publication. $609 \quad$ http://dx.doi.org/10.1037/a0039294

610 De Vries H, Netto WJ, Hanegraaf PLH. 1993. Matman-a program for the analysis of sociometric 611 matrices and behavioural transition matrices. Behaviour 125: 157-175. 
612 Ducoing AM, Thierry B. 2003. Withholding information in semifree-ranging Tonkean macaques 613 (Macaca tonkeana). Journal of Comparative Psychology 117(1): 67-75.

614 Emery NJ, Lorincz EN, Perrett DI, Oram MW, Baker CI. 1997. Gaze following and joint 615 attention in rhesus monkeys (Macaca mulatta). Journal of Comparative Psychology 616 111(3): 286-293.

Emery NJ. 2000. The eyes have it: the neuroethology, function and evolution of social gaze. Neuroscience and Biobehavioral Reviews 24: 581-604.

Flavell JH. 1992. Perspectives on perspective taking. In H. Beilin, \& P. Pufall (Eds), Piaget's

620

621

622

623

624

625

626

627

628

629

630

631

632

633

634 Theory: prospects and possibilities (pp. 107-139). Hillsdale, NJ: Erlbaum. Flombaum JI, Santos LR. 2005. Rhesus monkeys attribute perceptions to others. Current Biology 15: 447-452.

Goossens BMA, Dekleva M, Reader SM, Sterck EHM, Bolhuis JJ. 2008. Gaze following in monkeys is modulated by observed facial expressions. Animal Behaviour 75: 1673-1681.

Hare B, Call J, Agnetta B, Tomasello M. 2000. Chimpanzees know what conspecifics do and do not see. Animal Behaviour 59: 771-785.

Hare B. 2001. Can competitive paradigms increase the validity of experiments on primate social cognition? Animal Cognition 4: 269-280.

Hare B, Call J, Tomasello M. 2001. Do chimpanzees know what conspecifics know? Animal Behaviour 61: 139-151.

Hare B, Addessi E, Call J, Tomasello M, Visalberghi E. 2003. Do capuchin monkeys, Cebus apella, know what conspecifics do and do not see? Animal behaviour 65: 131-142.

Heyes CM. 1998. Theory of mind in nonhuman primates. Behavioral and brain sciences 21: 101-148. 
635 Itakura S. 2004. Gaze-following and joint visual attention in nonhuman primates. Japanese 636 Psychological Research 46(3): 216-226.

637 Johnson CM, Karin-D’Arcy MR. 2006. Social attention in nonhuman primates: a behavioral 638 review. Aquatic Mammals 32(4): 423-442.

639 Kaminski J, Call J, Tomasello M. 2008. Chimpanzees know what others know, but not what they 640 believe. Cognition 109: 224-234.

641 Kano F, Call J. 2014. Cross-species variation in gaze following and conspecific preference 642 among great apes, human infants and adults. Animal Behaviour 91: 136-149.

643 Karin-D’Arcy MR, Povinelli DJ. 2002. Do chimpanzees know what each other see? A closer $644 \quad$ look. International Journal of Comparative Psychology 15: 21-54.

645 Krachun C, Call J. 2009. Chimpanzees (Pan troglodytes) know what can be seen from where. 646 Animal Cognition 12: 347-331.

647 Lewis F, Butler A, Gilbert L. 2011. A unified approach to model selection using the likelihood 648 ratio test. Methods in Ecology and Evolution 2: 155-162.

649 Liebal K, Kaminski J. 2012. Gibbons (Hylobates pileatus, H. moloch, H. lar, Symphalangus 650 syndactylus) follow human gaze, but do not take the visual perspective of others. Animal 651 Cognition 15(6): 1211-1216.

652 MacLean EL, Sandel AA, Bray J, Oldenkamp RE, Reddy RB, Hare BA. 2013. Group size 653 predicts social but non-social cognition in lemurs. PLOS One 8(6): e66359. 654 doi:10.1371/journal.pone.0066359.

655 Micheletta J, Waller BM. 2012. Friendship affects gaze following in a tolerant species of 656 macaque, Macaca nigra. Animal Behaviour 83: 459-467. 
657 Moll H, Meltzoff AN. 2011. How does it look? Level 2 perspective-taking at 36 months of age. 658 Child Development 82(2): 661-673.

659 Overduin-de Vries AM, Spruijt BM, Sterck EHM. 2014. Long-tailed macaques (Macaca 660 fascicularis) understand what conspecifics can see in a competitive situation. Animal $661 \quad$ Cognition 17: 77-84.

662 Peignot P, Anderson JR. 1999. Use of experimenter-given manual and facial cues by gorillas 663 (Gorilla gorilla) in an object-choice task. Journal of Comparative Psychology 113(3): 253664260.

665 Povinelli DJ, Nelson KE, Boysen ST. 1990. Inferences about guessing and knowing by 666 chimpanzees (Pan troglodytes). Journal of Comparative Psychology 104(3): 203-210.

667 Povinelli DJ, Eddy TJ. 1996. What young chimpanzees know about seeing. Monographs of the 668 Society for Research in Child Development 61: 1-152.

669 Povinelli DJ, Vonk J. 2003. Chimpanzee minds: suspiciously human? Trends on cognitive $670 \quad$ sciences 7(4): 157-160.

671 Povinelli DJ, Vonk J. 2004. We don't need a microscope to explore the chimpanzee's mind. $672 \quad$ Mind \& Language 19(1): 1-28.

673 Premack D, Woodruff G. 1978. Does the chimpanzee have a theory of mind? Behavioural Brain $674 \quad$ Sciences 1: 515-526.

675 Ruiz A, Gómez JC, Roeder JJ, Byrne RW. 2009. Gaze following and gaze priming in lemurs. $676 \quad$ Animal Cognition 12: 427-434.

677 Sandel AA, MacLean EL, Hare B. 2011. Evidence from four lemur species that ringtailed lemur 678 social cognition converges with that of haplorhine primates. Animal Behaviour 81: 925679931. 
680 Shepherd SV. 2010. Following gaze: gaze-following behavior as a window into social cognition. 681 Frontiers in Integrative Neuroscience 4(5): 1-13.

682 Santos LR, Nissen AG, Ferrugia JA. 2006. Rhesus monkeys, Macaca mulatta, know what others 683 can and cannot hear. Animal Behaviour 71: 1175-1181.

684 Tomasello M, Call J, Hare B. 1998. Five primate species follow the visual gaze of conspecifics. 685 Animal Behaviour 55: 1063-1069.

686 Tomasello M, Hare B, Fogleman T. 2001. The ontogeny of gaze following in chimpanzees, Pan 687 troglodytes, and rhesus macaques, Macaca mulatta. Animal Behaviour 61: 335-343.

688 Tomasello M, Carpenter M, Call J, Behne T, Moll H. 2005. Understanding and sharing 689 intentions: the origins of cultural cognition. Behavioral and Brain Sciences 28: 675-735. 


\section{Figure 1 (on next page)}

\section{Figure 1}

Schema of the experimental apparatus used in the visual perspective-taking experiment. Macaques in area $A$ and $C$ were given access to the testing area $B$ where two pieces of food were placed. One piece was put on one of the two breeze blocks, i.e. visible by the two subjects (subjects in A and C), and another one was placed in and under the other breeze block, i.e. hidden from one of the two subject's view (subject in A). 


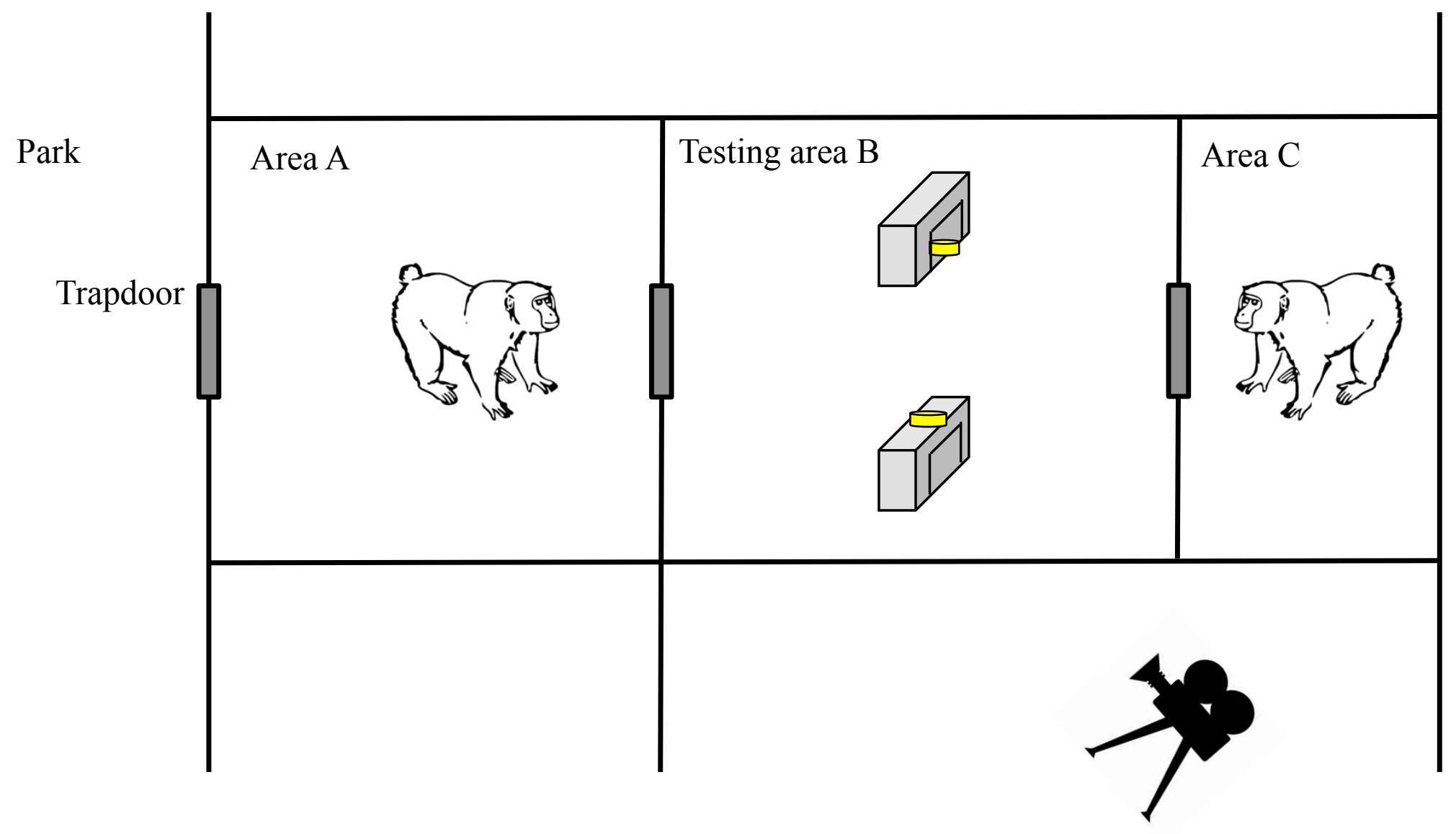




\section{Figure 2 (on next page)}

\section{Figure 2}

First direction choice taken by the subject able to see both pieces of food, i.e. the subordinate in the conditions 1 and 2 and the dominant in the conditions 3 and 4 , in the different experimental conditions. "No choice" category corresponds to cases where the subject did not enter in the testing area or entered and sat down in front of the trapdoor or entered and crossed the testing area through the two breeze blocks. "Choice towards food" category corresponds to cases where the subject heads for hidden or visible food. ${ }^{* * *} P<$ 0.0001 
PeerJ Manuscript to be reviewed

Subordinate sees both pieces of food

Simultaneous released

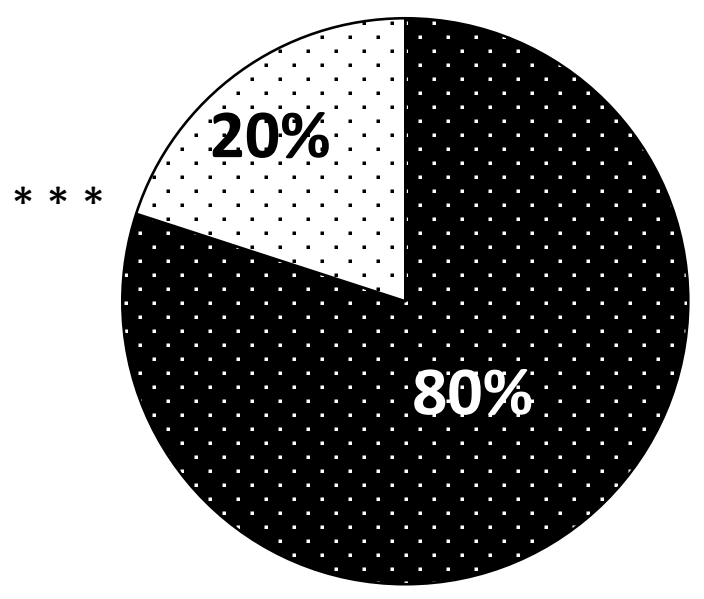

Head start for subordinate

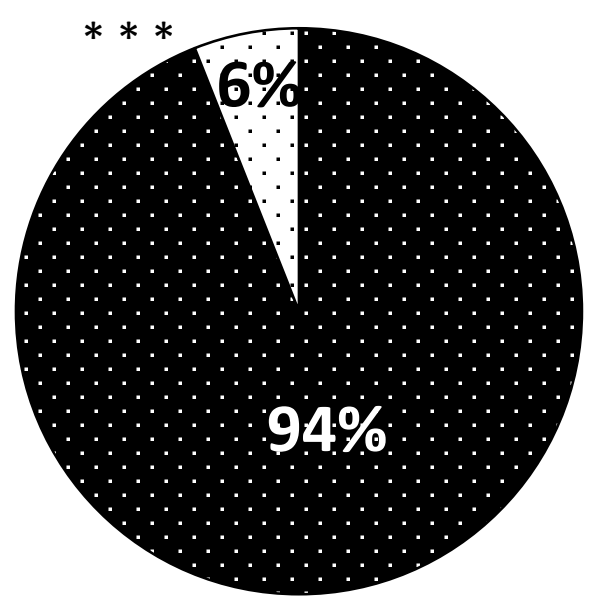

Dominant sees both pieces of food

Simultaneous released

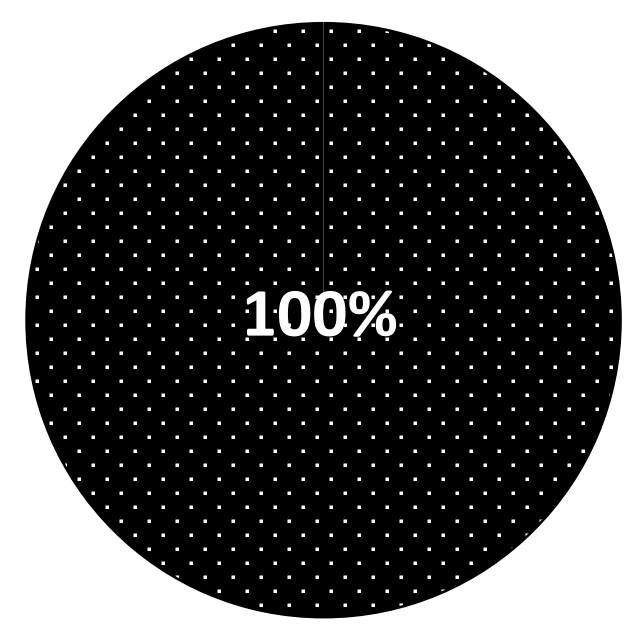

Head start for dominant

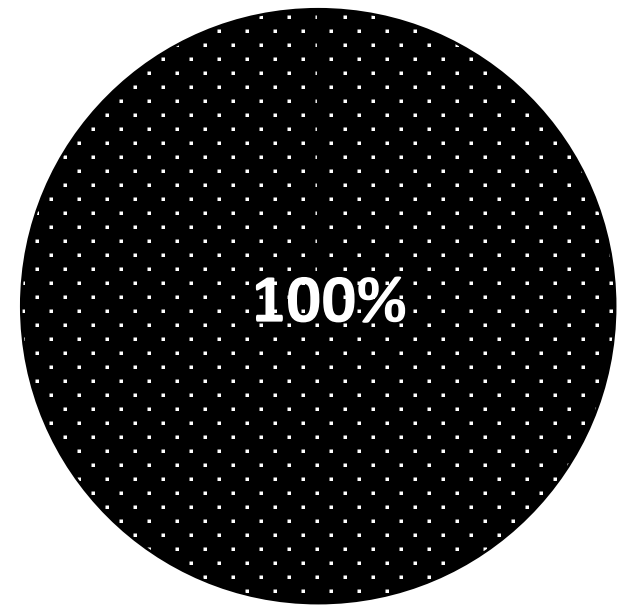

No choice Choice towards food (visible or hidden) 


\section{Figure 3 (on next page)}

Figure 3

First direction choice taken by the subject able to see both pieces of food, i.e. the subordinate in the conditions 1 and 2 and the dominant in the conditions 3 and 4, towards food (hidden or visible) in the different experimental conditions. ${ }^{* * *} P<0.0001$ 


\section{PeerJ

Subordinate sees both pieces of food

Simultaneous released

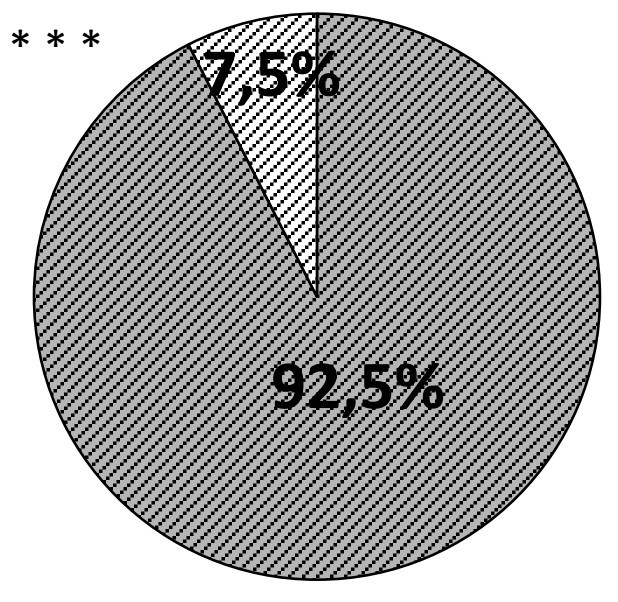

Head start for subordinate

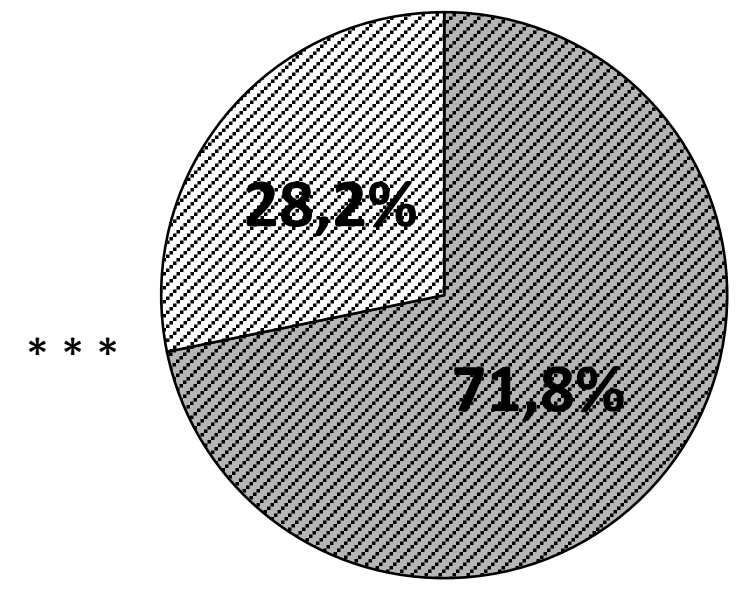

\section{Dominant sees both pieces of food}

Simultaneous released

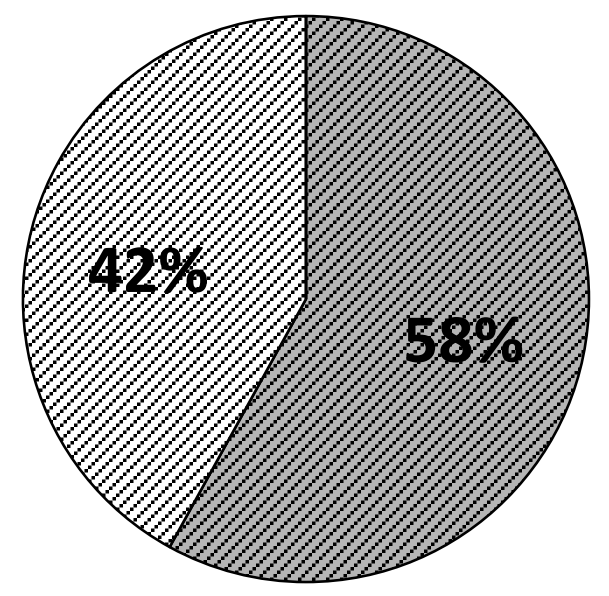

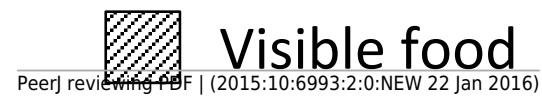

Head start for dominant

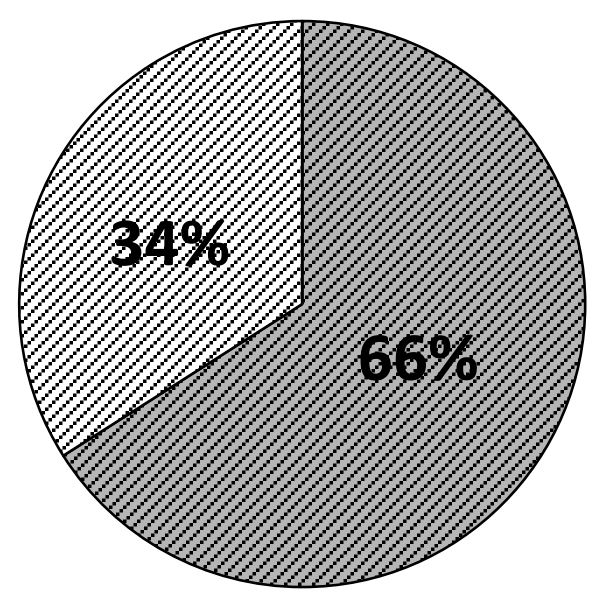

Hidden food 


\section{Figure 4 (on next page)}

Figure 4

Outcome of encounters in the different experimental conditions. 
PSaldordinate sees both piecess of foodeviewed

Condition 1: Simultaneous released

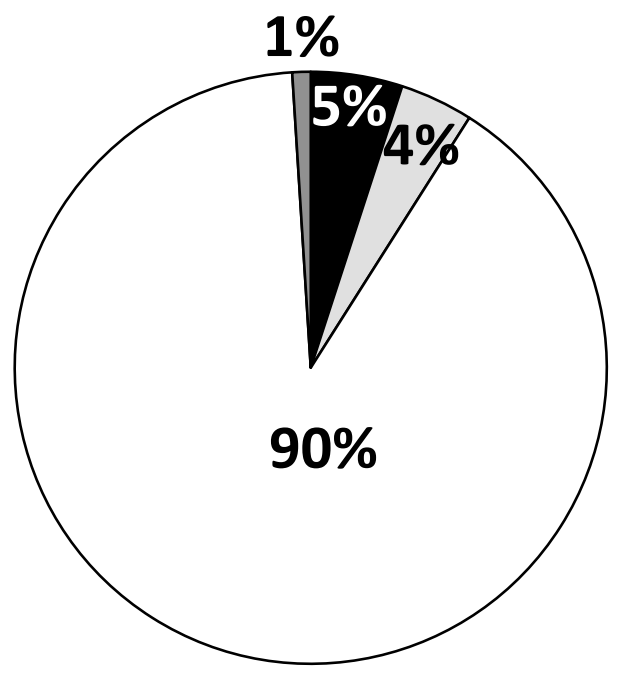

Condition 2: Head start for subordinate

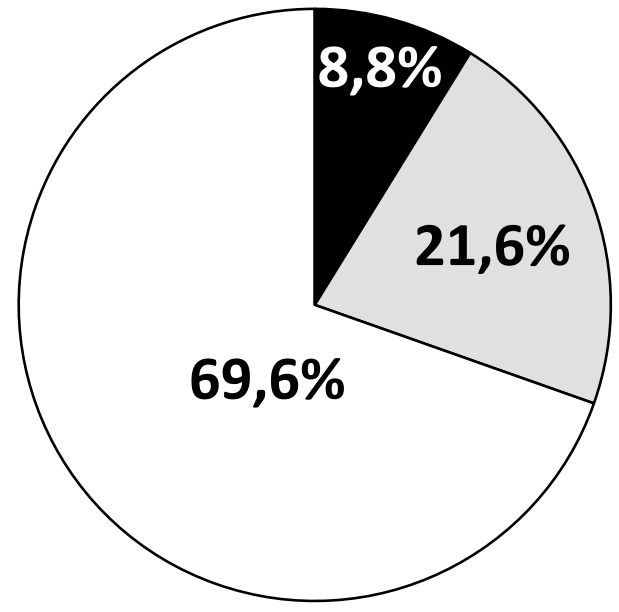

Dominant sees both pieces of food

Condition 4: Simultaneous released

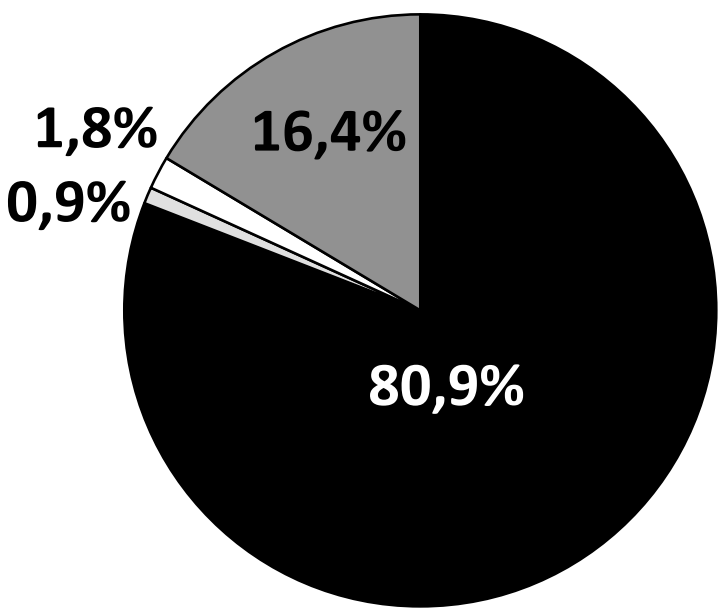

Condition 3: Head start for dominant

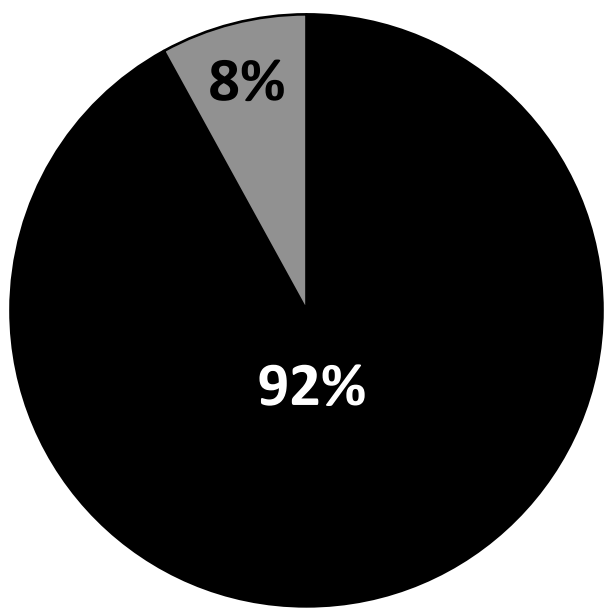

Dominant gets both

$\square$ Dominant gets visible piece of food, subordinate gets hidden one Subordinate gets both 


\section{Table 1 (on next page)}

Table 1

Sex, age, hierarchical rank, number of trials as dominant, number of trials as subordinate and total number of trials of subjects. 


\begin{tabular}{|c|c|c|c|c|c|c|}
\hline Subject & Sex & Age (years) & \begin{tabular}{|l} 
Hierarchical \\
rank
\end{tabular} & $\begin{array}{l}\text { Number of trials as } \\
\text { dominant }\end{array}$ & $\begin{array}{l}\text { Number of trials as } \\
\text { subordinate }\end{array}$ & $\begin{array}{l}\text { Total number of } \\
\text { trials }\end{array}$ \\
\hline Lady & Female & 17 & 12 & 45 & 166 & 211 \\
\hline Yannick & Male & 5 & 13 & 6 & 197 & 203 \\
\hline Nereis & Female & 15 & 8 & 13 & 7 & 20 \\
\hline Nema & Female & 3 & 14 & 45 & 11 & 56 \\
\hline Vishnu & Male & 8 & 6 & 32 & 20 & 52 \\
\hline Uruk & Male & 9 & 2 & 6 & 0 & 6 \\
\hline Wallace & Male & 7 & 5 & 75 & 0 & 75 \\
\hline Wotan & Male & 7 & 9 & 128 & 4 & 132 \\
\hline Walt & Male & 7 & 10 & 54 & 0 & 51 \\
\hline Shan & Male & 11 & 1 & 31 & 0 & 31 \\
\hline Nenno & Male & 2 & 19 & 0 & 30 & 30 \\
\hline
\end{tabular}




\section{Table 2 (on next page)}

Table 2

Hierarchical rank difference and number of trials per condition of tested dyads. 
Tested dyad (dominant subordinate)

Wallace - Yannick Wotan - Yannick

Walt - Yannick

Lady - Yannick

Nereis - Lady

Walt - Lady

Wotan - Lady

Nema - Lady

Vishnu - Yannick

Lady - Nenno

Shan - Yannick

Wallace - Wotan

Wallace - Vishnu

Uruk - Yannick

Wallace - Lady

Yannick - Nema

Uruk - Wotan

Nereis - Yannick

Wallace - Nereis

Wallace - Nema

Uruk - Lady

\begin{tabular}{|c|c|c|c|}
\hline $\begin{array}{l}\text { hierarchical rank } \\
\text { difference }\end{array}$ & $\begin{array}{l}\text { Number of trials condition } \\
1\end{array}$ & $\begin{array}{l}\text { Number of trials condition } \\
2\end{array}$ & \begin{tabular}{|l} 
Number of trials cc \\
3
\end{tabular} \\
\hline 8 & 10 & 8 & 7 \\
\hline 4 & 20 & 14 & 11 \\
\hline 3 & 3 & 5 & 4 \\
\hline 1 & 3 & 6 & 4 \\
\hline 4 & 3 & 3 & 3 \\
\hline 2 & 9 & 11 & 9 \\
\hline 3 & 16 & 18 & 15 \\
\hline 2 & 11 & 13 & 10 \\
\hline 7 & 7 & 8 & 10 \\
\hline 7 & 7 & 8 & 9 \\
\hline 12 & 8 & 7 & 6 \\
\hline 4 & 0 & 2 & 0 \\
\hline 1 & 3 & 8 & 5 \\
\hline 11 & 0 & 2 & 0 \\
\hline 7 & 0 & 3 & 2 \\
\hline 1 & 0 & 3 & 1 \\
\hline 7 & 0 & 1 & 0 \\
\hline 5 & 0 & 1 & 0 \\
\hline 3 & 0 & 3 & 2 \\
\hline 9 & 0 & 1 & 2 \\
\hline 10 & 0 & 0 & 0 \\
\hline
\end{tabular}




\section{Table 3(on next page)}

Table 3

Occurrences of first direction towards visible food item and occurrences of outcome 2 (Subordinate obtained two pieces of food) after subordinate chose to head for the visible piece of food in conditions 1 and 2 . 


\begin{tabular}{|c|c|c|c|c|c|c|c|}
\hline & Lady & Nema & Nenno & Nereis & Vishnu & Wotan & Yannick \\
\hline Subordinate headed for the visible food & 15 & 1 & 8 & 0 & 1 & 0 & 15 \\
\hline $\begin{array}{l}\text { Subordinate headed for the visible food and } \\
\text { obtained both pieces of food (outcome } 2 \text { ) }\end{array}$ & 9 & 0 & 6 & 0 & 0 & 0 & 8 \\
\hline
\end{tabular}

